\title{
Studies of the Crystalline Structure of Stretched Polyisobutylene
}

\author{
Irena SŁowikowska, Leszek Makaruk, Irena Daniewska, \\ and Maria JEDYNAK \\ Institute of Organic Chemistry and Technology, \\ Technical University, Warsaw, Poland.
}

(Received August 5, 1975)

\begin{abstract}
KEY WORDS Crystalline Structure / Light Scattering / Stretched Polyisobutylene /
\end{abstract}

Crystallinity in rubber-like polymers can be induced at higher than $T_{\mathrm{g}}$ temperatures if they are stretched. Stress crystallinity in rubber has been examined mainly by X-ray methods; in this way it was shown that the molecules are aligned along the axis of the stress. ${ }^{1-3}$

The existence of fibrous structures in stretched crystalline elastomers has been observed by Walters using an electron microscope. ${ }^{4}$ Yau and Stein $^{5}$ by the SALS method have found that natural cured rubber, when stretched up to $600 \%$, gives scattering patterns related to the orientation of the fibrous structure. The $V_{\checkmark}$ patterns were much more intense and distinctive that the $H_{v}$ ones, which did not change a lot during the deformation.

In this work we studied, by the SALS method, changes of both $V_{\mathrm{v}}$ and $H_{\mathrm{v}}$ patterns during the stress induced crystallization of uncured polyisobutylene. The formation of crystalline structure in stretched polyisobutylene was reported by Brill and $\mathrm{Halle}^{2}$ and Fuller with coworkers, ${ }^{3}$ who used X-ray method.

Investigations in our studies were carried out on two kinds of polyisobutylene: Oppanol B100 (molecular weight 100000) and Oppanol B200 (molecular weight 200000). The samples of polymers were prepared in the form of films by evaporation of their 1.5-\% solutions in chloroform. The solutions were poured on a mercury level and after the evaporation of the solvent the films were removed by means of an aluminium frame. $15 \times 10 \times 0.25 \mathrm{~mm}$ samples of the films were stretched to a definit length and were held between microscope slides in the immersion fluid (Canadian balsam) to prevent surface scattering from making an undue contribution. The samples were placed in the apparatus perpendicularly to a beam of parallel rays of polarised light of $6328 \AA$ wavelength obtained from a $\mathrm{He}-\mathrm{Ne}$ laser. The stretching direction of the films was set parallel to the vertical direction so that the effect of birefringence on the scattering pattern was minimized. In the case of Oppanol B100, we did not observe in all the region of elongations used in the investigations any scattering patterns indicating the formation of crystalline structures. It is probable that in polyisobutylene of this molecular weight the relaxation of stretching takes place very rapidly. For this reason systematic studies were carried out on samples of Oppanol B200, starting the measurement at $100 \%$ relative elongation. The first $V_{\nabla}$ scattering pattern indicating the formation of the crystalline phase was observed at $600 \%$ elongation (Figure 1). The shape of the picture was ellipsoidal and can be related to the first stage of the formation of anisotropic and oriented crystalline structure. However, these pictures were unstable and disappeared within several hours. The $H_{\mathrm{v}}$ patterns were not observed for this elongation. For the elongations beginning from $700 \%$, the $H_{\checkmark}$ and $V_{\checkmark}$ patterns had the shape of elongated four leaf clovers. The maximum intensity for both kinds of patterns was found along the direction of the transmitted ray, i.e., at zero scattering angle (Figure 1). The intensity decreases mono- 
I. Szowikowska, L. Makaruk, I. Daniewska, and M. Jedynak

$V_{\nabla}$

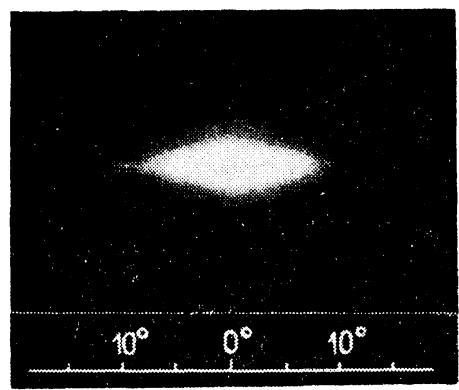

$600 \%$

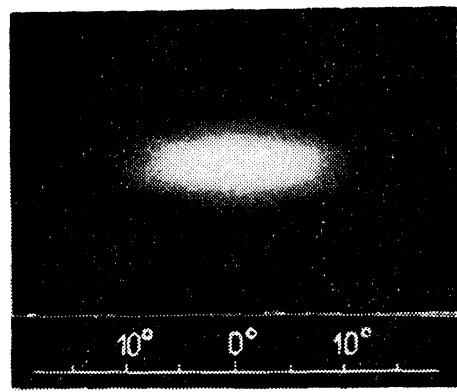

$700 \%$

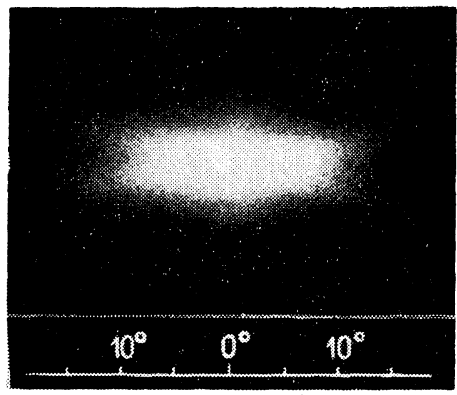

$800 \%$

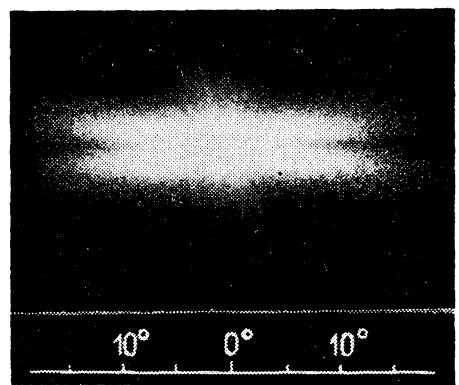

$900 \%$
$H_{\text {v }}$

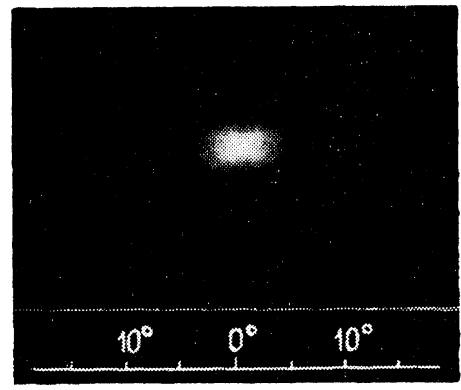

$700 \%$

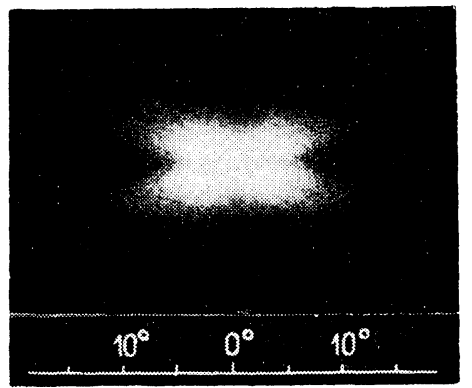

$800 \%$

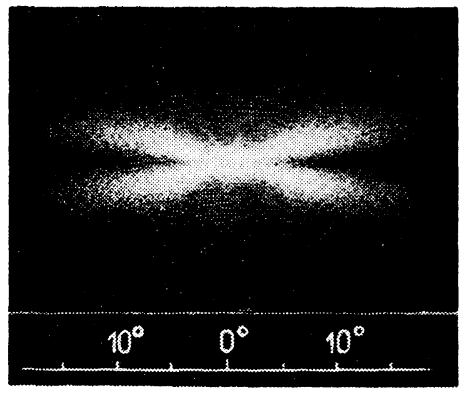

$900 \%$

Polymer J., Vol. 8, No. 2, 1976 
$V_{\mathrm{v}}$

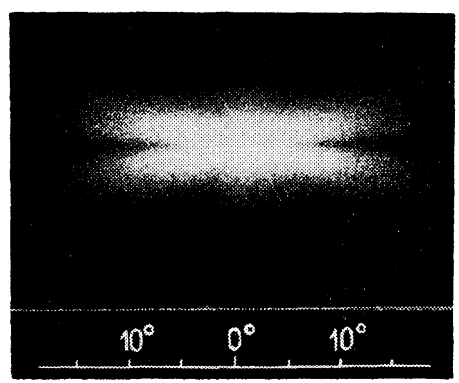

$1000 \%$

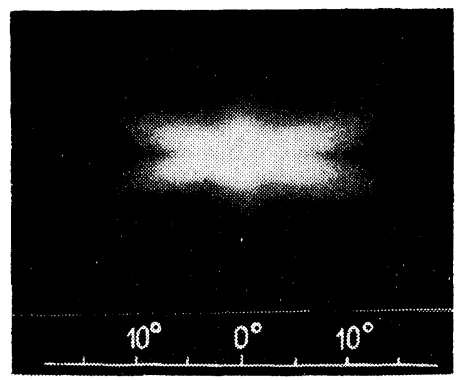

$1100 \%$

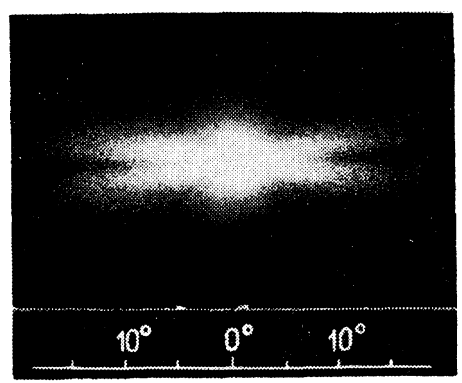

$1150 \%$
$H_{\text {v }}$

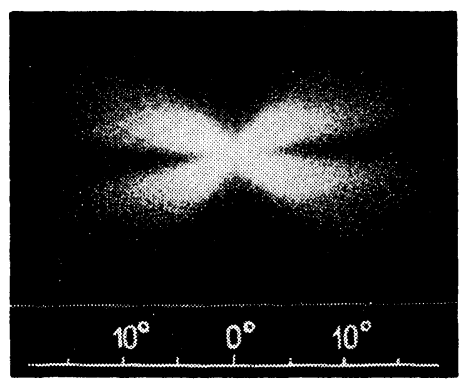

$1000 \%$

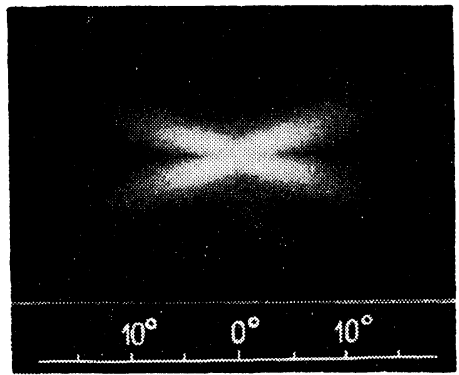

$1100 \%$

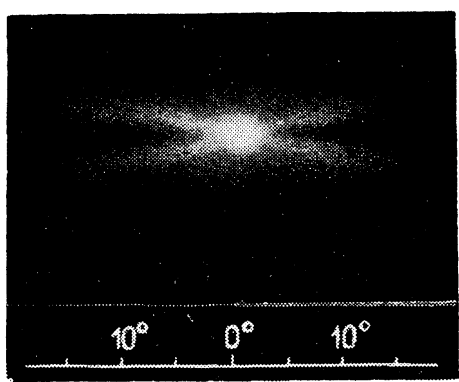

$1150 \%$

Figure 1. The change in $V_{\mathrm{v}}$ and $H_{\mathrm{v}}$ scattering patterns for polyisobutylene with percentage elongation. The stretching direction is vertical.

tonously with increasing scattering angle. The patterns were permanent and no relaxation phenomenon was observed even after several months of storage in the stretching state. All the $H_{\mathrm{v}}$ patterns were much more distinct and deformed than those obtained by Yau and $\operatorname{Stein}^{5}$ for stretched cured natural rubber.

The scattering patterns disappeared upon releasing the stress. This means that optical heterogeneities are not present in the unstretched samples.

The four leaf clover pattern with the maxi- mum intensity of scattering light at $\theta=0^{\circ}$ is typical for a random assembly of anisotropic rod-like structures. ${ }^{6-8}$ Depending on the angle $\omega$ between the optical axis and the axis of the rod the pattern is of 45 or $0-90^{\circ}$ type. The deformation of $0-90^{\circ} H_{\mathrm{v}}$ pattern (rods with $30^{\circ} 33^{\prime}<\omega<70^{\circ} 07^{\prime 7}$ ) was studied both experimentally $y^{6,9-13}$ and theoretically ${ }^{6,9,13}$ while the deformation of $\pm 45^{\circ} H_{\mathrm{v}}$ patterns (rods with $0 \leq \omega<30^{\circ} 33^{\prime}$ and $70^{\circ} 07^{\prime}<\omega \leq 90^{\circ 7}$ ) has not been investigated previously.

In order to confirm the presence and the 


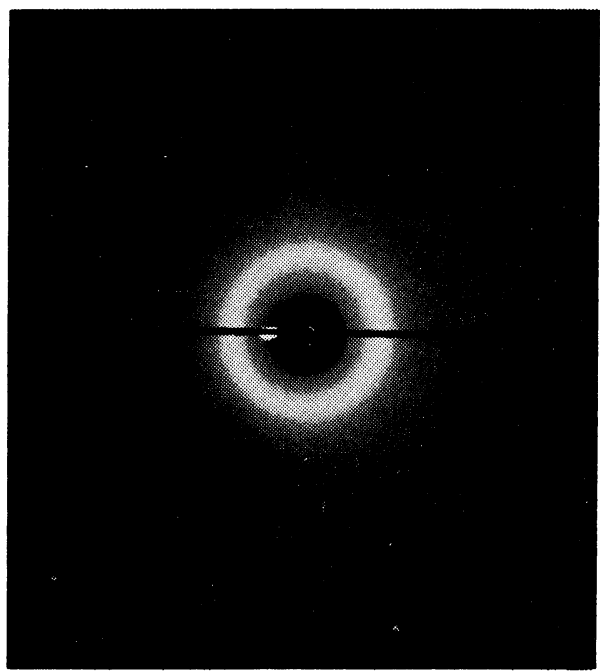

Figure 2. X-Ray photograph of amorphous polyisobutylene.

organization of the crystalline phase in stretched polyisobutylene we have carried out X-ray studies, by means of a TUR-60 (East Germany) apparatus and flat camera, using the Laue method. In these studies we were using $\mathrm{CuK}_{\alpha}$ radiation $(\lambda=1,54051 \AA)$ monochromatized by means of a nickel filter. The exposure time was $6 \mathrm{hr}$. Up to $600-\%$ elongation the samples were giving only an intense ring of the "halo" type due to scatter of X-rays by the amorphous phase (Figure 2). At elongations exceding 700\% we observed reflections due to the scatter of $\mathrm{X}$-rays by crystallites (Figure 3 ). X-Ray photographs of samples at higher elongations indicated that the intensity of the reflections was increasing with increasing elongation, but the angles at which these reflections were observed remain unchanged. According to Yau and Stein, ${ }^{14}$ who observed similar phenomena in their studies of the orientation crystallisation of natural and synthetic rubbers, this proves that the axes of the macromolecules in the crystallites remain parallel to the direction of stretching.

The intensity of the scatter by the amorphous phase decreased with increasing intensity of crystalline reflections.

As a result of this study we can say that the crystallisation of the investigated polyisobutylene depends on the molecular weight of the polymer and is formed by the organization of the rod-

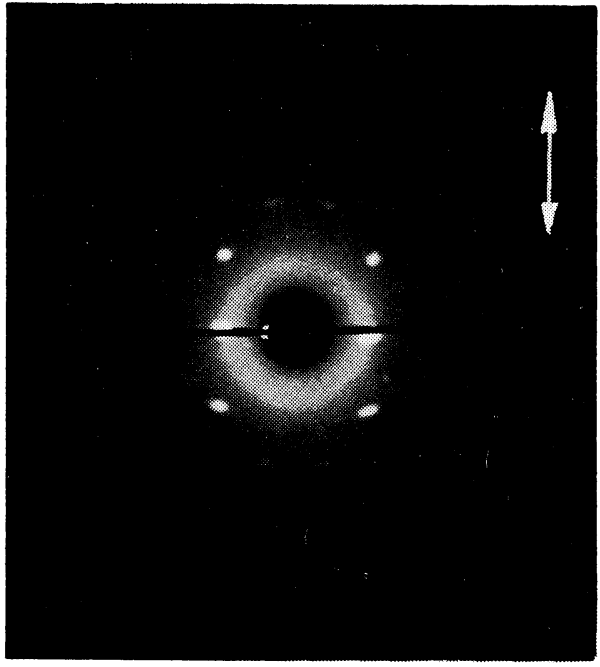

Figure 3. X-Ray photograph of polyisobutylene elongated $900 \%$.

like structures with their optical axes nearly parallel $\left(0^{\circ} \geq \omega>30^{\circ} 33^{\prime}\right)$ or perpendicular $\left(90^{\circ} \geq\right.$ $\left.\omega>70^{\circ} 07^{\prime}\right)$ to the rod axis.

\section{REFERENCES}

1. C. W. Bunn, Proc. Roy. Soc. London, A180, 40 (1942).

2. R. Brill and F. Halle, Naturwiss., 26, 12 (1938).

3. C. S. Fuller, C. J. Frosch, and N. R. Pape, J. Amer. Chem. Soc., 62, 1905 (1940).

4. M. H. Walters, J. Polym. Sci., Part A-1, 3091 (1963).

5. W. Yau and R. S. Stein, ibid., Part B-2, 231 (1964).

6. M. B. Rhodes and R. S. Stein, ibid., Part A-2, 7, 1539 (1969).

7. Y. Murakami, N. Hayashi, T. Hashimoto, and H. Kawai, Polymer J., 4, 452 (1973).

8. T. Hashimoto, Y. Murakami, N. Hayashi, and H. Kawai, ibid., 6, 132 (1974).

9. N. Hayashi, Y. Murakami, M. Moritani, T. Hashimoto, and H. Kawai, ibid., 4, 560 (1973).

10. J. C. W. Chien and E. P. Chang, Macromolecules, 5, 610 (1972).

11. G. C. Adams and R. S. Stein, J. Polym. Sci., Part A-2, 6, 31 (1968).

12. M. Moritani, N. Hayashi, A. Utsuno and $\mathbf{H}$. Kawai, Polymer J., 2, 74 (1971).

13. R. J. Samuels, J. Polym. Sci., Part A-2, 7, 1197 (1969).

14. W. Yau and R. S. Stein, ibid., Part A-2, 6, 1 (1968). 